\title{
Aplicabilidade de um Modelo de Planejamento Estratégico em uma Organização Sem Fins Lucrativos
}

\section{Elsi do Rocio Cardoso Alano ${ }^{1}$}

1 Doutora em Administração - FEI-SP, Mestre em Administração - UP, Mestre em Ciênas Agronômicas - UFPR e Especialista em Administração - UFPR. Professora do Curso de Gestão e Empreendedorismo da UFPR - Setor Litoral, Brasil. E-mail: elsi.rocio@gmail.com

RESUMO: O presente estudo teve como objetivo verificar a aplicabilidade de um Modelo de Planejamento Estratégico em uma Organização sem fins Lucrativos, na área de Ciências Sociais, mais especificamente em Administração, e consecutivamente seus resultados, dado ao fato de que os modelos desenvolvidos nesta área nem sempre são aplicados e tampouco seus resultados. Consecutivamente apresentou-se a organização que aplicou o referido modelo, a Congregação das Irmãs do Imaculado Coração de Maria - Sociedade Educação e Caridade (SEC) e seu Planejamento Estratégico em seu interstício de quatro anos. Considerando a realização de um Estudo de Caso primou-se pelas técnicas de pesquisa qualitativa em que se utilizou como metodologia entrevistas e análise documental. Como resultado foi possível detectar que o modelo adotado é plenamente aplicável, haja vista que foram identificados, no processo, os elementos presentes no referido modelo. Identificou-se que a adoção do Modelo pautou-se pelo não distanciamento da Instituição de seu objetivo primordial. Alguns benefícios advindos da realização do planejamento estratégico puderam ser levantados, tal como um melhor posicionamento da instituição frente às suas demandas.

Palavras-chave: Planejamento Estratégico, Terceiro Setor, Organizações Sem Fins Lucrativos, Administração.

ABSTRACT: The present study aimed to verify the applicability of a Model of Strategic Planning in a Nonprofit Organization in the area of social Sciences, specifically in Administration and consecutively its results, given the fact that the models developed in this area do not always are applied, nor its results. Consecutively presented to the organization that has applied that model, the congregation of the sisters of the Immaculate Heart of Mary - Education and Charitable Society (SEC) and its Strategic Plan in their interstitium of four years. Given the above, and considering planning as a multiyear, the theoretical review and the results of the present study was to elucidate the possible overall goal this article. Whereas the realization of a Case Study excelled themselves by qualitative research techniques that were as interviews and documentary analysis methodology. As a result it was possible to detect that the adopted model is fully applicable, given that were identified in the process, the elements present in this model. It was identified that the adoption of the model was guided by not distancing the institution from its primary goal. Some benefits from the completion of the strategic planning a better positioning of the institution forward their demands.

Keywords: Strategic Planning, Third Sector, Nonprofit Organizations, Administration. 


\section{INTRODUÇÃO}

O desenvolvimento da administração como área de conhecimento teve como foco principal até recentemente as empresas privadas voltadas à obtenção de lucro, sendo marginal as preocupações dos pesquisadores em relação às organizações sem fins lucrativos, que englobam as do Estado e as da Sociedade Civil (OLIVEIRA; ROSS; ALTIMEYER, 2005; McHatton et al., 2011). Mas dados objetivos principais das chamadas empresas de mercado (voltadas ao lucro) e a dificuldade do Estado em prover a sociedade com serviços apropriados, mais recentemente o estudo relacionado às Organizações da Sociedade Civil, as quais não visam lucro e não fazem parte do aparelho do Estado, vem chamando a atenção de pesquisadores da área (NIEBOER, 2011).

Mas deve-se ressaltar que já em 1995 Drucker manifestava-se a respeito delas, apontando que quatro elementos são necessários para que obtenham sucesso: um plano, marketing, pessoas e dinheiro (DRUCKER, 1995).

Atualmente, tem-se claro que tais elementos são fundamentais, visto que o acirramento da concorrência afeta não apenas as empresas que tradicionalmente existem para gerar lucro, mas também as organizações da sociedade civil (OLIVEIRA; ROSS; ALTIMEYER, 2005; KOTLER; ANDREASEN, 1996), pois muitas apresentam escopos e ideais análogos e, em última análise, concorrem pela atenção da sociedade e por recursos públicos e privados de pessoas físicas e jurídicas para operacionalizarem seus ideais (MCHATTON et al., 2011).

Inclusive, entidades públicas e privadas que financiam as causas por meio dessas organizações demandam processos profissionais de gestão, o que reforça de maneira contundente a necessidade de uma estrutura teórica que contribua para a eficácia e a eficiência gerencial (BRYSON, 1988; BEGGY, 2002; CHAHIM; PRAKASH, 2014).

Desta forma, o planejamento estratégico destaca-se como uma ferramenta gerencial de grande importância para qualquer tipo de organização, seja ela com o objetivo básico de obter lucro, seja ela sem fins lucrativos, pois auxilia a alocação de recursos, possibilita a priorização de estratégias e ações, sendo utilizado como ferramenta de gestão (MCHATTON et al., 2011; MARA, 2000; DRUCKER, 1995).

Mas poucos são os modelos específicos de planejamento estratégico para organizações sem fins lucrativos, muito embora as peculiaridades dessas instituições possam implicar a impossibilidade de se utilizar os modelos tradicionais, além da própria resistência dos gestores dessas entidades (BRYSON, 1988; BEGGY, 2002).

Com base nos ditos poucos modelos específicos existentes até 2005, Oliveira, Ross e Altimeyer (2005) propuseram um modelo conceitual, o qual foi adotado recentemente como base pela Congregação das Irmãs do Imaculado Coração de Maria - Sociedade Educação e Caridade - SEC para a elaboração do seu planejamento estratégico 2012-2017 (CONGREGAÇÃO, 2012).

Trata-se, portanto, de uma oportunidade rara, visto que no campo da Administração muitos modelos conceituais ou teóricos acabam por não ser implementados ou mesmo discutidos mais profundamente em trabalhos posteriores.

Embora o desenvolvimento científico não se norteie pela aplicabilidade ou mesmo pela 
utilidade, é fato que no campo das ciências sociais aplicadas, dentro do qual encontra-se a Administração, é desejável que as propostas e os resultados dos estudos, além de contribuir para a evolução do conhecimento da área, também contribua para o desenvolvimento das empresas e demais instituições que por ela possam ser estudadas ou se assemelhem.

Assim sendo, o objetivo deste artigo foi verificar a aplicabilidade do modelo de planejamento estratégico para organizações sem fins lucrativos de Oliveira, Ross e Altimeyer (2005).

Além da do referencial teórico pertinente, foi realizado um estudo de caso na Congregação das Irmãs do Imaculado Coração de Maria, conforme será detalhado na metodologia.

\section{ORGANIZAÇÕES DA SOCIEDADE CIVIL OU TERCEIRO SETOR}

Franco (2000) enfatiza que a classificação de uma organização como sendo do terceiro setor, em oposição ao setor privado e público, não é precisa devido ao fato de o terceiro setor também ser privado. Também apresenta restrições no que se refere a organizações sem fins lucrativos, pois nesta categoria pode-se abranger todo o setor público que também, em tese, não possui o lucro como finalidade.

Mas é fato que ainda hoje tais organização vem sendo designadas indistintamente por diversos termos, entre eles: organizações da sociedade civil, organizações não governamentais (ONG's), setor de economia social, terceiro setor ou setor sem fins lucrativos. À parte a discussão acerca da terminologia, por não fazer parte do escopo do presente trabalho, faz-se mister pontuar que essas organizações são privadas, e que não há apropriação do lucro excedente que possa originar, devendo ele, em existindo, constituir um patrimônio impessoal favorável a um determinado fim ou missão (MOORE, 2000; OLIVEIRA; ROSS; ALTIMEYER, 2005).

Paton (2003) corrobora e complementa afirmando que não é preciso avaliá-las como não governamentais, porque existe o setor privado lucrativo. Também designá-las como organizações sociais não abrange todos os aspectos, visto que nesta categoria inserem-se organizações híbridas, como por exemplo, aquelas com e sem fins lucrativos de ação social, de parcerias Inter setoriais, cooperativas e até relações de negócios norteadas socialmente.

Diante do exposto, pode-se conceituar uma organização sem fins lucrativos como uma instituição que provém da iniciativa privada, que disponibiliza bens, serviços e ideias visando a melhoria da qualidade de vida de uma sociedade. De maneira simples e direta, as organizações sem fins lucrativos existem para desempenhar missões sociais (MOORE, 2000).

Ao longo deste trabalho, visando respeitar as denominações principais utilizadas pelos autores dos trabalhos utilizados, os termos Organizações da Sociedade Civil, Organizações sem Fins Lucrativos e Terceiro Setor são tidos como sinônimos e referem-se ao objeto em discussão.

Para se definir, caracterizar ou enquadrar uma organização sem fins lucrativos da sociedade civil, os seguintes critérios devem ser atendidos, a saber (IBGE, 2004):

- Privadas, não integrantes, portanto, do aparelho de Estado. 
- Sem fins lucrativos, isto é, organizações que não distribuem eventuais excedentes entre os proprietários ou diretores, e que não possuem como razão primeira de existência a geração de lucros, podem até gerá-los, desde que aplicados nas atividades fins.

- Institucionalizadas, isto é, legalmente constituídas.

- Auto-administradas ou capazes de gerenciar suas próprias atividades.

- Voluntárias, à medida que podem ser constituídas livremente por qualquer grupo de pessoas, isto é, a atividade de associação ou de fundação da entidade.

Segundo Fernandes (1994), este setor congrega o conjunto de iniciativas provenientes da sociedade voltadas à produção de bens públicos, como a conscientização para os direitos da cidadania ou a prevenção de doenças transmissíveis. Constitui-se, de organizações que não integram o Estado nem a iniciativa privada com fins lucrativos.

Para Albuquerque (2006), as organizações do Terceiro Setor possuem elementos similares em termos de características, ações e projetos, e, na forma de condução perante a sociedade, conforme seguem:

a) adotam ações distintas do governo: aumentam as ações privadas;

b) estabelecem contraponto às atuações do mercado: existe a valorização dos interesses coletivos;

c) existe um aumento do tamanho dos elementos dos quais são compostas: crescem os valores político e econômico das ações voluntárias sem fins lucrativos;

d) se instituem como visão integradora da vida pública: designam sinergia entre ações públicas e privadas.

Subjacentemente, Salamon (2012) aponta cinco características que precisam ser encontradas em organizações desse tipo, a saber:

a) organizadas: é necessário que haja uma rotina de trabalho mesmo que a organização não esteja formalizada de maneira legal; devem contar com conselhos e realizar reuniões periódicas que tenham estruturação interna e objetivos formais;

b) privadas: não apresentam vínculo institucional com o governo;

c) lucros distribuídos: a apuração dos lucros auferidos deve ser revertida em prol da organização ou da comunidade na qual está inserida; ou seja, não distribuem seus lucros entre funcionários e proprietários, de maneira diversa ao procedimento padrão de organizações privadas.

d) autogovernáveis: são organizações independentes que tenham a possibilidade de ser sustentáveis, não sendo dependentes do setor público ou privado;

e) voluntárias: que apresentam algum tipo de atividade voluntária, seja no âmbito do trabalho prestado, seja em termos de financiamento, como por exemplo, recebimento de doações.

Silva (2010) aponta, ainda, como característica comum em organizações do terceiro setor a presença de fortes valores sociais, pois estas são criadas por indivíduos dispostos a conseguir mudanças no âmbito social, sendo desta forma, empreendedores sociais. 
No que se refere a essas organizações, Cruz (2009) considera ser fundamental alguns aspectos em termos de gestão estratégica: transparência, sobrevivência, qualidade dos serviços e capacidade de articulação. E, visando estes aspectos, faz-se necessário desenvolver um modelo de gestão específico a essas organizações.

\section{PLANEJAMENTO ESTRATÉGICO EM ORGANIZAÇÕES SEM FINS LUCRATIVOS}

Whittington (2002) analisa a estratégia partindo de quatro abordagens genéricas: a abordagem clássica, a abordagem evolucionária, processualista e a abordagem sistêmica. $\mathrm{Na}$ abordagem clássica busca-se um planejamento racional; a evolucionária traduz-se pelo termo "lei da selva"; a abordagem processualista faz a acomodação pragmática da estratégia ao processo passível de falhas das organizações; e, por fim, na abordagem sistêmica encontram-se ideias relativistas que consideram múltiplos elementos para o planejamento estratégico.

No entanto, Wilson e Jarzabkowski (2004, p.12) ressaltam que "[...] o campo da estratégia constitui uma guerra por territórios repleta de argumentos analíticos e teóricos que lembram os longos e intensos debates sobre a teoria das organizações nos anos 1960 e 1970". Acrescentam ainda que "[...] a estratégia não deveria ser considerada como um longo período de pensamento formulação da estratégia seguido por um longo período de ação - implementação da estratégia" (Wilson; Jarzabkowski, 2004, p.13)

Corroborando, Mintzberg (2000) destaca cinco definições para estratégia: 1- a estratégia é compreendida como um plano; 2) estratégia vista como um padrão; 3) a ideia de estratégia como posição; 4) estratégia percebida como perspectiva, caracterizando o modo de operação da organização e 5) a estratégia vislumbrada como "truque", abrangendo as manobras concretizadas para suplantar um concorrente.

Ressalte-se a importância do envolvimento e participação dos colaboradores da organização no processo de formulação e de implementação da estratégia, devendo-se, inclusive, capacitá-los a essas atividades (MINTZBERG, 2004).

Diante do exposto pode-se dizer que a partir da forma com que a organização interpreta as demandas competitivas e socioculturais presentes no contexto ambiental, no qual está inserida, ou ainda, para o qual desenvolve suas ações, a organização deve se estruturar e definir suas estratégias, tendo por finalidade o atendimento de seus interesses.

Fundamentalmente, vale ressaltar que o desenvolvimento da missão para uma organização do terceiro setor é essencial para que a mesma alcance o sucesso esperado porque é imprescindível manejar todos os distintos grupos de interesse da organização para que adotem e confiem em um objetivo coletivo.

De acordo com Drucker (1995), apenas a partir de uma definição precisa da missão, que se constitui na motivação de existência da organização, tornam-se possíveis, claros e realistas os objetivos da mesma. A definição da missão de uma organização é um processo complexo e arriscado, mas somente a partir dela se pode constituir políticas, desenvolver estratégias, aplicar recursos e dar início as atividades. Desta forma, uma organização pode ser administrada, pretendendo atingir uma excelente performance. 
Tradicionalmente, o planejamento estratégico pode ser considerado uma sequência de procedimentos analíticos que permite a definição de objetivos e estratégias para alcançáIos (NICOLAE, 2008; MINTZBERG, 2004), permite o vislumbre de oportunidades e ameaças, fraquezas e fortalezas, podendo ser mais ou menos formal (MINTZBERG, 2004; OFORI, ATIOGBE, 2012).

No entanto há diferenças importantes entre as organizações com e sem fins lucrativos e, também, entre as organizações da sociedade civil e as do Estado, que devem ser consideradas para se obter desempenhos satisfatórios com a gestão de cada uma delas. Tais diferenças decorrem basicamente de suas finalidades, o que implica diferenças na intensidade das forças ambientais exercidas sobre cada uma delas, conforme apresentado no Quadro 1. Além disso, o contexto da organização também deve ser levado em consideração, a fim de que as adaptações necessárias, em qualquer que seja o modelo adotado, sejam feitas de maneira apropriada (BRYSON, 2010).

Quadro 1 - Tipos de organizações e forças ambientais dominantes

\begin{tabular}{|l|l|l|}
\hline Organização Principal & Forças Ambientais Dominantes & Foco \\
\hline Sem Fins Lucrativos & $\begin{array}{l}\text { Missão/valores/competição/financiadores governamentais/sistema políti- } \\
\text { co/clientes/necessidades sociais/públicos interessados/grupos de defesa } \\
\text { do terceiro setor/governança/regulamentações. }\end{array}$ & Social \\
\hline Com Objetivo de Lucro & $\begin{array}{l}\text { Concorrência/clientes/acionistas/capacidade oganizacional/globalização/ } \\
\text { inovação e tecnologia/política de governo. }\end{array}$ & Mercado \\
\hline Públicas & $\begin{array}{l}\text { Sistema político, eleições, lobistas, serviços públicos, legislação, socieda- } \\
\text { de. }\end{array}$ & Político \\
\hline
\end{tabular}

FONTE: Adaptado de Fottler (1981) e de Akingbola (2013).

O uso do planejamento estratégico como ferramenta pelas organizações do terceiro setor é de grande importância, porque consiste em um método sistemático de definição de objetivos, estratégias, ações e as conduz mesmas a obter vantagens como uma melhor análise do ambiente no qual está inserida, auxiliar os gestores na reflexão sobre os direcionamentos necessários, a possibilidade de dimensionar as necessidades de capacitação, e dimensionar o desempenho, entre outras (ALVES JÚNIOR; FONTENELLE, 2009).

Um estudo realizado por Nieboer (2011), que teve por objetivo verificar o uso do planejamento estratégico por proprietários de conjuntos habitacionais sem fins lucrativos. Usando como base o modelo de Kotler (2006, p. 50), os resultados mostram três diferenças fundamentais, a saber (NIEBOER, 2011, p. 380): a) A formulação da estratégia depende não apenas dos objetivos do negócio, mas também de objetivos advindos de instâncias superiores das organizações, mas também de atores externos e internos ligados à política institucional que rege a finalidade social das organizações. b) Esses atores podem possuir políticas e análises próprias. c) Os princípios políticos influenciam igualmente, como a missão, os objetivos das organizações.

Outro estudo, realizado por Abdalkrim (2013), que teve por objetivo verificar o relacionamento entre o planejamento estratégico e o desempenho em organizações privadas sem fins lucrativos, aponta que todas as variáveis consideradas (declaração de missão, implementação, análise externa e interna, e avaliação e controle) correlacionam-se positivamente em nível estatístico significativo com o desempenho. 


\subsection{Modelo de Planejamento Estratégico de Oliveira, Ross e Altimeyer (2005)}

A partir dos modelos tradicional de planejamento estratégico (KOTLER, 2006; MINTZBERG, 2004; ANSOFF, 1993) e dos específicos para instituições sem fins lucrativos de Bryson (1988) e de Oster (1995), além das percepções provenientes da revisão bibliográfica realizada na ocasião, Oliveira, Ross e Altimeyer (2005) propuseram um modelo, uma vez que foram observadas deficiências nos modelos existentes. No Quadro 2 pode-se observar um comparativo dos modelos que deram base para o que fora proposto.

Quadro 2-Comparação dos modelos de Brysson, Oster e Tradicional.

\begin{tabular}{|l|l|l|l|}
\hline & Brysson & Oster & Tradicional \\
\hline Amberação com o & $\begin{array}{l}\text { Compreende que as defini- } \\
\text { ções de conduta devem se } \\
\text { dar a partir da análise dos } \\
\text { ambientes interno e externo }\end{array}$ & $\begin{array}{l}\text { Considera a análise externa como } \\
\text { suficiente para a definição dos } \\
\text { objetivos }\end{array}$ & $\begin{array}{l}\text { Os objetivos são definidos a partir da } \\
\text { análise interna e externa }\end{array}$ \\
\hline Missão & $\begin{array}{l}\text { A missão baseia-se nos } \\
\text { stakeholders }\end{array}$ & $\begin{array}{l}\text { Não considera a influência dos } \\
\text { stakeholders para a definição da } \\
\text { missão }\end{array}$ & $\begin{array}{l}\text { Considera a influência dos interessa- } \\
\text { dos "financistas" para a definição dos } \\
\text { objetivos }\end{array}$ \\
\hline Objetivos & $\begin{array}{l}\text { Não são definidos claramen- } \\
\text { te objetivos }\end{array}$ & $\begin{array}{l}\text { Os objetivos são claramente defini- } \\
\text { dos }\end{array}$ & Os objetivos são claramente definidos \\
Visão & $\begin{array}{l}\text { A visão é definida a partir } \\
\text { das estratégias }\end{array}$ & $\begin{array}{l}\text { Não considera a definição da visão } \\
\text { e dos valores }\end{array}$ & $\begin{array}{l}\text { Considera a definição de visão e } \\
\text { valores }\end{array}$ \\
\hline Modelo reativo ao ambiente & $\begin{array}{l}\text { Modelo proativo em relação ao } \\
\text { ambiente }\end{array}$ & $\begin{array}{l}\text { Modelo proativo em relação ao am- } \\
\text { biente }\end{array}$ \\
\hline
\end{tabular}

FONTE: Oliveira, Ross e Altimeyer (2005).

O modelo proposto por Oliveira, Ross e Altimeyer (2005) buscou considerar os conceitos da metodologia tradicional de planejamento estratégico, mas fundamentalmente as especificidades destas organizações. E, sendo uma proposta teórica, os autores apontam nas conclusões a sugestão de validação do modelo, visando a sua aplicabilidade.

Para os autores, a formação de uma organização sem fins lucrativos se dá por meio da coordenação de valores, princípios e visão de uma ou um grupo de pessoas em prol de objetivos sociais, originando uma "causa social", que significa o motivo da existência de uma organização sem fins lucrativos (OLIVEIRA; ROSS; ALTIMEYER, 2005). Assim, a "causa social" diz respeito ao direcionamento maior da organização, a exemplo da missão nas empresas "de mercado", a qual possui estreita relação com os valores, princípios e visão da organização - que devem ser condizentes com as dos seus fundadores.

A visão, os princípios e os valores do fundador ou idealizador da organização devem permeá-la e suportar as suas ações. Aliado a essas forças, a "causa social" deve originar a visão, os valores e os princípios da instituição, de forma que sirvam de base para a o planejamento estratégico propriamente dito.

Abaixo são apresentadas as cinco etapas para o planejamento estratégico, que devem ser balizadas pelas peculiaridades dessas instituições (OLIVEIRA; ROSS; ALTIMEYER, 2005): 1. Análise externa e análise interna: diz respeito à busca de oportunidades e ameaças e de pontos fortes e a melhorar, possível pela avaliação e projeção dos impactos gerados pelas forças sociais e organizacionais; 
2. Fixação dos objetivos: diz respeito à definição do que se quer obter em um período de tempo específico. No caso de organizações do terceiro setor indica-se como objetivos legítimos número de pessoas atendidas, projetos realizados, etc. Ressalte-se que os objetivos devem ser condicionados pelos princípios e valores organizacionais, pelas oportunidades e ameaças, e pelos pontos fortes e a melhorar (provenientes das análises externa e interna); 3. Estabelecimento de estratégias e das ações: diz respeito à definição dos caminhos e atitudes que permitirão alcançar os objetivos pré-definidos;

4. Implementação: diz respeito à colocação em prática das estratégias e ações estabelecidas;

5. Monitoramento, controle e avaliação: diz respeito à validação do processo realizado, à medida que busca conhecer e mensurar a adequação da realidade ao que fora planejado. A depender do resultado dessa etapa, deve-se optar pela continuidade do processo ou pela sua revisão integral ou de parte, conforme o que for indicado na averiguação.

Assim, os valores, princípios, visão e a própria "causa social" sofrem influência dos públicos de relacionamento dessas organizações, fazendo com que o planejamento estratégico propriamente dito considere os anseios e as necessidades dos stakeholders, uma vez que o relacionamento tende a ser de mutualismo e cooperação, buscando a harmonia e os apoios necessários ao seu desenvolvimento e ao cumprimento das suas funções. Na Figura 1 segue o modelo proposto para organizações sem fins lucrativos. 
Figura 1 - Modelo de planejamento estratégico

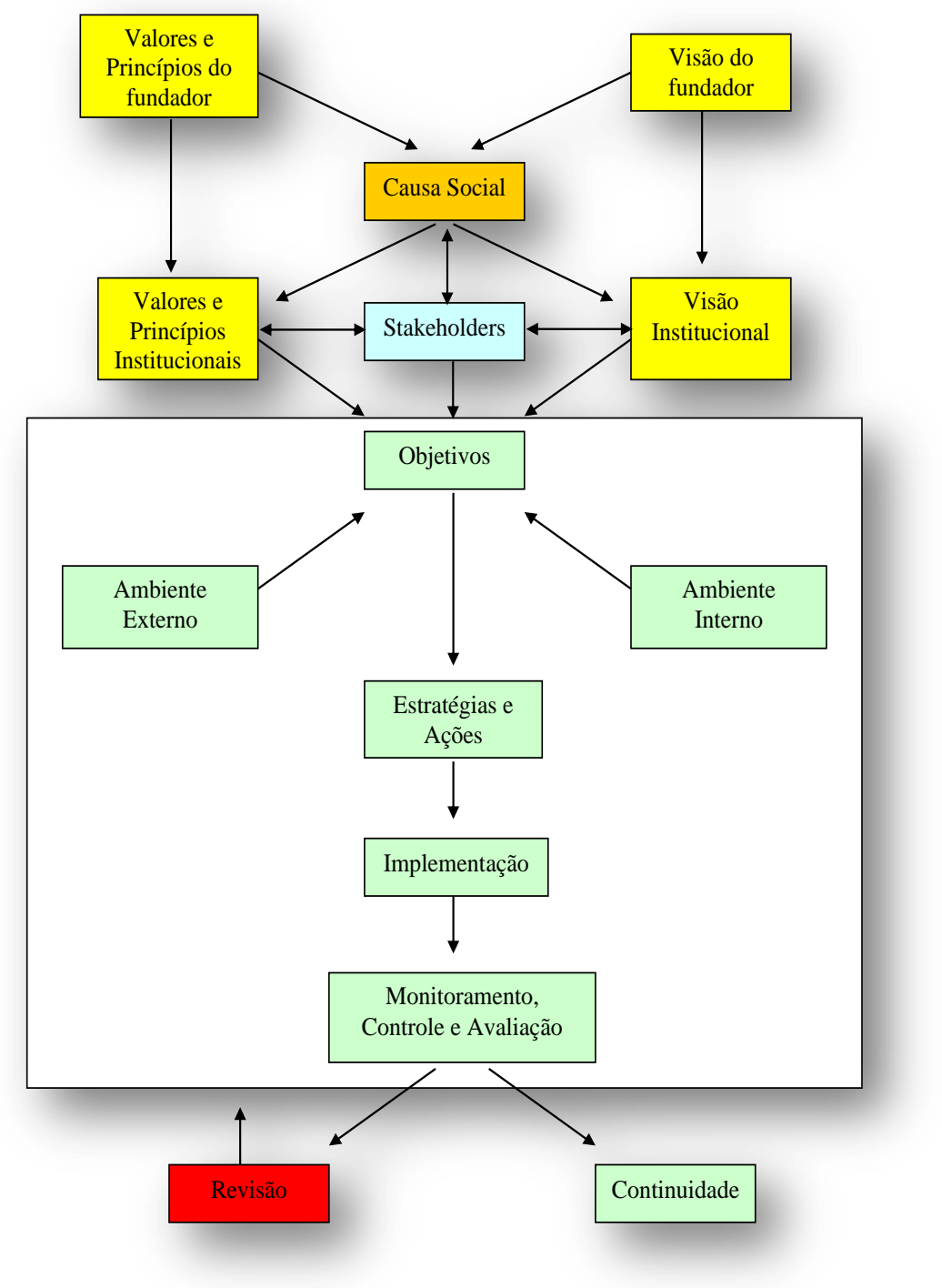

FONTE: Oliveira, Ross e Altimeyer (2005).

Os autores ressaltam, ainda, que os valores e princípios da organização sejam passados de forma clara aos colaboradores para que o comprometimento produza os resultados esperados, e que tanto os colaboradores, quanto a sociedade, conheçam a "causa social" e até mesmo o plano estratégico, a fim de minimizar dificuldades naturais da gestão (OLIVEIRA; ROSS; ALTIMEYER, 2005).

\section{METODOLOGIA}

A abordagem da pesquisa foi qualitativa interpretativista, considerando-se as abordagens paradigmáticas propostas por Guba e Lincoln (2000) e por Gephart (2004). Significa dizer que sua natureza é relativista, o que pressupõe ser a realidade composta de significados objetivos e subjetivos de cada ator envolvido no contexto social que compõe a ação estudada. 
O objetivo do estudo interpretativista é fazer a descrição dos significados e entendimentos, e por conseguinte, a principal tarefa do pesquisador será produzir descrições dos significados que os atores sociais atribuem a um mesmo fenômeno (GUBA; LINCOLN, 2000; GEPHART, 2004). Buscou-se entender os significados no contexto em que o fenômeno ocorre e as divergências sistemáticas entre significados.

Minayo $(2007$, p. 23) entende que a pesquisa qualitativa "considera que há uma relação dinâmica entre o mundo real e o sujeito, isto é, um vínculo indissociável entre o mundo objetivo e a subjetividade do sujeito que não pode ser traduzido em números."

De acordo com Creswell (1994), quando o pesquisador deseja explorar uma ou poucas entidades ou fenômeno (casos), limitado pelo tempo e atividade (grupo social) e espera recolher informações, utilizando uma variedade de procedimentos de coleta de dados durante um período de tempo, deve-se utilizar o estudo de caso.

Na definição de Mitchell (1983), os estudos de caso são uma forma de organizar dados sociais, preservando a característica unitária do objeto social a ser estudado.

Yin (2004) afirma que estudo de caso é uma pesquisa empírica que investiga um fenômeno contemporâneo dentro de seu contexto real, quando o limite entre o fenômeno e o contexto não são claramente definidos e isso implica a utilização de múltiplas origens de evidências.

Assim, o método adotado para o desenvolvimento da pesquisa foi o estudo de caso, baseado em Yin (2004). Becker (1999) e Yin (2004) assinalam que as pesquisas estruturadas em torno do estudo de caso utilizam estratégias diversificadas de coleta de dados, já que se trata de uma análise detalhada e aprofundada de uma unidade particular. Esse conjunto de evidências, característica deste tipo de estudo, permite que se confrontem informações (YIN, 2004). Para tanto, foram realizadas três entrevistas com a responsável pela condução do planejamento estratégico na instituição mencionada, no segundo semestre de 2013, além da análise de documentos fornecidos por ela.

Foi utilizado um roteiro semi-estruturado, baseado no modelo de planejamento estratégico de Oliveira, Ross e Altimeyer (2005), além de questionamentos relacionados às dificuldades e benefícios que o modelo teria propiciado.

A seguir são apresentados os resultados da pesquisa.

\section{APRESENTAÇÃO E DISCUSSÃO DOS RESULTADOS}

\subsection{Descrição da Instituição e Contextualização}

A Congregação das Irmãs do Imaculado Coração de Maria - SEC é uma Instituição Beneficente de Assistência Social com mais de 100 anos de atuação na prestação de serviços socioassistenciais a pessoas e grupos em situação de vulnerabilidade social, situada em Porto Alegre, RS (CONGREGAÇÃO, 2012).

Em 2010, houve um reordenamento das atividades desenvolvidas da instituição, passando a ser a mantenedora direta de 08 Serviços de Proteção Social Básica direcionados ao atendimento de crianças, adolescentes e familiares no Estado do Rio Grande do Sul (CON- 
GREGAÇÃO, 2012). Também é responsável pela direção e coordenação pedagógica de estabelecimentos de terceiros que desenvolvem serviços de convivência e fortalecimento de vínculo - proteção social básica e especial de média complexidade (CONGREGAÇÃO, 2012).

A instituição passou ao longo de sua existência por diversas conformações e modificações que buscavam sempre acompanhar as demandas e exigências contextuais para se firmar em seus princípios, contudo, atualizando e qualificando seus processos, gestão e ações (CONGREGAÇÃO, 2012).

Assim, a partir do contexto da Lei Orgânica da Assistência Social - LOAS, Política Nacional de Assistência Social - PNAS, do Sistema Único de Assistência Social - SUAS e da Tipificação Nacional dos Serviços Socioassistenciais que determina que a instituições de educação e caridade definam estratégias e procedimentos para o exercício de suas atividades, em 2011 a instituição estudada firmou compromisso de elaborar o seu planejamento estratégico para a área de assistência social.

Ficou determinado que este deveria seguir o seguinte processo: construção do planejamento participativamente de maneira a englobar os diversos atores envolvidos - direções, equipes técnicas, educadores/ as, prestadores de serviços e usuários (CONGREGAÇÃO, 2012).

\subsection{O Processo de Planejamento}

Desta forma, os procedimentos metodológicos para o desenvolvimento do planejamento estratégico foram (CONGREGAÇÃO, 2012):

1. Envio de carta circular às coordenadoras provinciais e diretoras dos estabelecimentos motivando a participação e o delineando os passos do processo;

2. Composição da Equipe;

3. Elaboração de uma matriz metodológica para conhecer as realidades locais (diagnóstico);

4. Encontro com a equipe de sistematização para o aprofundamento das metodologias de construção do trabalho participativo;

5. Aplicação do instrumento e recebimento de dados;

6. Encontro da equipe de sistematização para a tabulação dos dados;

7. Devolução dos dados aos estabelecimentos para conhecimento, apreciação e complementação;

8. Novo encontro da equipe para aprofundar e complementar o diagnóstico e preparar o seminário da área;

9. Seminário para finalizar o diagnóstico e definir os objetivos e ações;

10. Encontro da equipe para sistematização final do documento.

Os valores institucionais da Congregação, são pautados na vida humana como prioridade, com postura de solidariedade e defesa da justiça social e com o compromisso com os menos favorecidos economicamente diante de uma visão sistêmica e gestão em rede mantendo as questões humanas éticas e inclusivas.

Houve um empenho bastante grande para alinhar os princípios institucionais ao legado 
deixado por Bárbara Maix, fundadora da congregação. O que relata a entrevistada é que "evidentemente buscando atualizá-los em consonância com a realidade hodierna em seus diferentes contextos sócio culturais, a linguagem, as conquistas e normativas da política de Assistência Social".

Destacam-se como marca inegociável: a) $\mathrm{O}$ amor aos pobres, seu protagonismo e libertação nos processos; a defesa da vida e a promoção da cidadania; a formação ética e humana pautada na verdade, na justiça e no perdão, e b) O cultivo de uma mística abrangente plural ecumênica capaz de sustentar a motivação e as convicções de todos que abraçam esta causa.

Assim, observa-se que os valores e princípios institucionais estão constantemente sendo revisitados e alinhados aos da fundadora, e contribuindo para a definição da causa social abraçada pela instituição, conforme preconizado pelo modelo de Oliveira, Ross e Altimeyer (2005).

A visão institucional orienta que a organização seja referência na defesa e promoção da vida; Já a visão da fundadora, em razão de sua própria origem, teve como meta a defesa da vida, os pobres como forma de concretização da vontade de Deus.

No que concerne à visão, a entrevistada acrescenta que a da fundadora e a da instituição estão integradas. Nas palavras dela, referindo-se à visão institucional, "esta visão estava enraizada no sonho e legado deixado por nossa fundadora...tendo isso como forma de concretização".

Portando, também em relação à visão institucional, há influência da fundadora, bem como contribuição dela para a causa social defendida mostra aderência com o modelo de Oliveira, Ross e Altimeyer (2005).

As causas sociais abraçadas pela instituição contemplam: a assistência a crianças e adolescentes em situação de vulnerabilidade e risco social, a defesa da dignidade e direitos das mulheres, em particular as que são vítimas de violência e exploração e o enfrentamento ao tráfico de pessoas. Contudo, os avanços propiciaram mudanças e continua promovendo tais mudanças em detrimento as formas de atuar, as quais transcendem a prática assistencial do passado, e atualmente acontece com uma metodologia mais pedagógicopolítica, planejada e articulada. Entretanto, para que tais movimentos pudessem e possam continuar, requer-se uma aguçada sensibilidade que não permita acomodar-se nem ficar indiferente ao clamor dos pobres; a amplitude das demandas destas causas pede um processo de humanização e diálogo que garantam relações construtivas e protagonizadoras e defensoras de direitos, tarefas que remetem sempre aos princípios fundacionais e desafiam a atualizá-los e neles se afirmar.

Pôde-se notar a adequação do modelo de Oliveira, Ross e Altimeyer (2005) nesse âmbito, uma vez que as causas, acabam por tomar formas de atuações, serviços e ações por influência dos seus principais públicos de relacionamentos (stakeholders), mas interagindo, também, com a visão, os valores e os princípios institucionais.

A adoção do modelo permitiu tratar de maneira clara e específica os objetivos, conforme preconizado. Tais objetivos foram construídos a partir de um diagnóstico amplo em que considerou-se: a realidade externa e interna da instituição, o contexto socioeconômico 
e cultural, os públicos com os quais interagem e a realidade interna da instituição. A entrevistada declarou, ainda, que fizeram uso de um método baseado na matriz FOFA (Forças, Oportunidades, Fraquezas e Ameaças) para melhor definirem as estratégias da instituição.

A implementação está sendo realizada pelos responsáveis definidos no momento oportuno, visto que o período para o qual o plano foi elaborado é de cinco anos. Apesar disso, houve um avanço significativo na qualidade dos processos, segundo a entrevistada. Por enquanto, pôde-se perceber que possuir um instrumento comum para fundamentar e orientar as práticas contribui para:

- as equipes, que estão mais seguras e criativas,

- a melhoria da interação cotidiana entre colaboradores e entre esses e os usuários dos serviços;

- os posicionamentos, que estão mais claros e frente às demandas.

Segundo a entrevistada, quanto ao acompanhamento, cada estabelecimento realiza o seu em momentos que julgarem apropriados, sendo que alguns o realizam de forma mais efetiva e sistemática, outros tem mais dificuldades, contudo, encontram-se em processo. Já a revisão, é realizada trimestralmente nos estabelecimentos e anualmente em um encontro com representantes dos estabelecimentos.

De acordo com a entrevistada, o modelo de Planejamento Estratégico para Organizações sem fins Lucrativos proposto por Oliveira, Ross e Altimeyer (2005) contribuiu para o desenvolvimento do Plano da Congregação, o qual sem dúvida somou no processo de elaboração, e consequentemente contribuiu para a compreensão metodológica do planejamento estratégico, para além de uma plano empresarial, ajudando o grupo a garantir a dimensão da filosofia e especificidades das organizações religiosas sem fins lucrativos.

Vale ressaltar que o referido modelo foi utilizado em um dos seminários formativos da Congregação, com uma contribuição importante para o grupo firmar a identidade e definir os passos metodológicos utilizados.

Para a entrevistada, a aplicabilidade do modelo foi possível pela contribuição coletiva do grupo que trabalhos em sua elaboração, o qual possui bastante experiência.

\section{CONSIDERAÇÕES FINAIS}

Com o objetivo de verificar aplicabilidade do modelo de planejamento estratégico em organizações sem fins lucrativos de Oliveira, Ross e Altimeyer (2005), este estudo contribui para o conhecimento relativo ao assunto. Além disso, poucos são os modelos conceituais e teóricos que efetivamente são aplicados ou testados em condições reais na área de Administração, em relação ao total desenvolvido - o que também denota a relevância do trabaIho.

No estudo de caso da organização Congregação das Irmãs do Imaculado Coração de Maria - SEC, ficou clara a importância do desenvolvimento do planejamento estratégico de maneira compartilhada por toda a equipe responsável pela gestão, colaboradores e indivíduos atendidos por ela - uma forma que talvez possa ser própria para organizações dessa 
natureza.

Um elemento fundamental que pareceu frágil no caso, embora bastante claro no modelo de planejamento, é o fato de o acompanhamento mensal não ser reportado à mantenedora. Nesse sentido, ainda que a frequência possa ser repensada, a comunicação com a mantenedora a respeito do andamento da implementação e dos resultados relacionados ao plano estratégico deve ser formal, a fim de que se constitua uma base de conhecimento que possa ser utilizada em planejamentos futuros.

Outra questão que chama a atenção no caso estudado foi o amplo horizonte de tempo para o qual o planejamento foi realizado. Embora seja importante que instituições definam planos de longo prazo, sobretudo as que operam no terceiro setor e com causas sociais, ter planos anuais é fundamental para que as realizações possam ser observadas, para que as estratégias e ações definidas sofram menor influência dos fatores macro e micro ambientais e, ainda, para que o acompanhamento, o controle e os ajustes que se fizerem necessários não requeiram demasiado tempo para serem efetivados ou mesmo implementados.

Por seu turno, pelo fato de o modelo de Oliveira, Ross e Altimeyer (2005) ser genérico e não abordar pormenorizadamente os detalhes para se trabalhar cada elemento nele constante, a instituição estudada fez uso de matrizes de análise para a formulação de estratégias e ações - o que implica que os envolvidos na elaboração do plano tenham conhecimentos básicos de Administração e de planejamento estratégico empresarial.

O planejamento estratégico pode ser considerado uma ferramenta bastante proveitosa para a gestão da instituição, pois sua adoção contribuiu para a formação de uma nova cultura organizacional, mais fundamentada nas demandas sociais, em vista das constantes mudanças de cenário que podem afetar as comunidades que são atendidas pela organização.

As limitações do presente trabalho decorrem eminentemente do método de pesquisa adotado e do foco em um modelo específico. Assim, sugere-se a realização de estudos semelhantes em organizações sem fins lucrativos que atuem, por exemplo, com outras causas sociais, de forma que se possa obter novas contribuições, seja para reforçar o modelo de Oliveira, Ross e Altimeyer (2205), seja para trazer novos elementos à discussão acerca do tema.

\section{REFERÊNCIAS}

ABDALKRIM, G. M. The impact of strategic planning activities on private sector organizations performance in Sudan: an empirical research. International Journal of Business and Management, v. 8, n. 10, p. 134-143, 2013.

AKINGBOLA, K. A Model of strategic nonprofit human resource management. Voluntas, $v$. 24, s.n., p. 214-240, 2013.

ALBUQUERQUE, A. C. Terceiro Setor: história e gestão de organizações. São Paulo: Summus, 2006.

ALVES JÚNIOR, M. D.; FONTENELE, R. E. S. Planejamento Estratégico como Ferramenta de 
Gestão para Organizações do Terceiro Setor - Um Estudo dos Empreendimentos Sociais Apoiados pela Ashoka. ENCONTRO DE ESTUDOS EM ESTRATÉGIA, 4. 2009, Recife. Anais... Recife, 2009.

ANSOFF, I. Implantando a administração estratégica. São Paulo: Atlas, 1993.

BECKER, H. Observação social e estudos de caso sociais. In: Métodos de pesquisa em ciências sociais. São Paulo: Hucitec, 1999.

BEGGY, T. Adapting the traditional business plan into social enterprises. Pennsylvania CPA Journal, 2002, p. 22-23.

BRYSON, J. M. Strategic planning for public and nonprofit organizations. San Francisco: Jossey-Bass Publishers, 1988.

. The future of public and nonprofit strategic planning in the United States. Pu-

blic Administration Review, v. 70, n. S1, p. 255-267, 2010.

CHAHIM D., PRAKASH A. NGOization, foreign funding, and the nicaraguan civil society. Voluntas, v. 25, s.n., p. 487-513.

CONGREGAÇÃO das Irmãs do Imaculado Coração de Maria - Sociedade Educação e Caridade. Planejamento Estratégico da Área de Assistência Social - ANOS 2012-2017. Porto Alegre: ICM-SEC, 2012.

CRESWELL, J. Research design: Qualitative \& Quantitative Approaches. Thousand Oaks: Sage, 1994

CRUZ, R. N. Análise da motivação dos empreendedores no novo paradigma do século 21: um estudo de caso com empreendedores do primeiro, segundo e terceiro setor de Brasília. 2009. Dissertação (Mestrado em Administração). São Paulo, 2009. Disponível em: http://sustentavelnapratica.net/arquivos/MonografiaRN.pdf. Acesso em out./2013.

DRUCKER, P. Administração de Organizações sem Fins lucrativos: princípios e práticas. São Paulo: Pioneira, 1995.

FERNANDES, R. C. O que é o Terceiro Setor? In: Ioschpe, E. et al. 3o Setor: desenvolvimento social sustentado. Rio de Janeiro: Paz e Terra, 1997.

FOTTLER, M. D. Is management really generic? Academy of Management Review, v. 6, n. 1, p. 1-12, 1981.

FRANCO, R. C. O Marketing nas Organizações Sem Fins Lucrativos. In: BRITO, Carlos Melo; LENCASTRE, Paulo. (Coord.). Os Horizontes do Marketing. Lisboa: Verbo, 2000.

GEPHART, R. P. From the editors: qualitative research and the Academy of Management Journal. Academy of Management Journal, v. 47, n. 4, 2004.

GUBA, E.; LINCONLN, Y. Paradigmatic controversies, contradictions, and emerging confluences. In: DEZIN, N. K.; LINCOLN, Y. Handbook of qualitative research. Thousand Oaks: Sage, 2000.

IBGE. As Fundações Privadas e Associações sem fins lucrativos no Brasil 2002. Rio de Janeiro: IBGE, 2004.

MARA, C. M. A Strategic planning process for a small nonprofit organization - a hospice example. Nonprofit Managemente \& Leadership, v. 11, n. 2, p. 211-223, 2000.

MINAYO, M. C. S. O desafio do conhecimento: pesquisa qualitativa em saúde. São Paulo: Hucitec-Abrasco, 1992. 
MINTZBERG, H. O processo da estratégia. Porto Alegre: Bookman, 2001. . Ascensão e Queda do Planejamento Estratégico. Porto Alegre: Bookman, 2004.

MITCHELL, J. C. Case and situation analysis. The Sociological review, v. 33, p. 187-211, 1983.

NICOLAE, I. Strategic management in nonprofit and public organistions. Management and Marketing Journal, v. 6, n. 1, p. 185-191, 2008.

NIEBOER, N. Strategic planning process models: a step further. Property Management, v. 29, n. 4, p. 371-382, 2011.

OFORI, D.; ATIOGBE, E. Strategic planning in public universities: a developing country perspective. Journal of Management and Strategy, v. 3, n. 1, 2012.

OLIVEIRA, B.; ROSS, E. S.; ALTIMEYER, H. Y. Proposta de um modelo de planejamento estratégico para instituições sem fins lucrativos. Revista da FAE. Curitiba, v. 8, n. 1, p. 69-80, 2005.

OSTER, S. M. Strategic management for nonprofit organizations. Oxford: Oxford University Press, 1995.

PATON, R. Managing and measuring social enterprises. Sage Publications, 2003.

MCHATTON, P. A.; BRADSHAW, W.; GALLAGHER, P. A.; REEVES, Rebecca. Results from a strategic planning process: benefits for a nonprofit organization. Nonprofit Management \& Leadership, v. 22, n. 2, p. 233-249, 2011.

SALAMON, L. The state of monprofit america. New York: Bookings institute, 2012.

SILVA, C. G.: Management, legislation and funding sources in the Brazilian third sector: a historical perspective. São Paulo: Ilus, 2010.

WILSON, D. C.; JARZABKOWSKI, P. Thinking and acting strategically: new challenges for interrogating strategy. European Management Review, v. 1, n. 1, p. 14-20, 2004.

WHITTINGTON, R. O que é estratégia. São Paulo: Thompson, 2002.

YIN, R. K. Estudo de caso: planejamento e método. São Paulo: Bookman, 2004. 